\title{
Optimization of cryo-treated EDM variables using TOPSIS-based TLBO algorithm
}

\author{
CHINMAYA PRASAD MOHANTY ${ }^{1, *}$, MANTRA PRASAD SATPATHY ${ }^{2}$, \\ SIBA SANKAR MAHAPATRA ${ }^{3}$ and MANAS RANJAN SINGH ${ }^{4}$ \\ ${ }^{1}$ School of Mechanical Engineering and Building Sciences, VIT University, Vellore 632014, India \\ ${ }^{2}$ School of Mechanical Engineering, KIIT University, Bhubaneswar 751024, India \\ ${ }^{3}$ Department of Mechanical Engineering, National Institute of Technology, Rourkela 769008, India \\ ${ }^{4}$ Silicon Institute of Technology, Bhubaneswar 751024, India \\ e-mail: chinmaymohantymech@gmail.com
}

MS received 19 July 2017; revised 20 October 2017; accepted 27 November 2017; published online 11 April 2018

\begin{abstract}
In order to machine hard and high-strength-to-weight ratio materials, electrical discharge machining $(\mathrm{EDM})$ process is extensively used in aerospace, automobile and other industrial applications. However, high erosion of tool and improper selection of machining variables have emerged as a major obstruction to achieve productivity in this direction. High erosion of tool not only enhances the cost of machining but also increases the machining time by causing interruption during machining. Therefore, proper selection of machining variables and tool material life are the two vital aspects for the tool engineers working in EDM. In view of this, the present work proposes an extensive experimental investigation and optimization of machining variables of cryogenically treated brass tool materials on machining competences of Inconel 718 workpiece. The study primarily highlights the outcome of cryogenically treated soaking duration of tools along with other important process variables, viz. discharge current, open-circuit voltage, pulse-on time, duty factor and flushing pressure, on the performance measures such as electrode wear ratio (EWR), surface roughness and radial over-cut. The study revealed that soaking duration in deep cryo-treatment of the electrode is a significant variable to achieve improved machining characteristics. The performance measures are converted into equivalent single performance measure by calculating the relative closeness coefficient by the techniques for order preferences by similarity to ideal solution (TOPSIS) approach. Finally, a novel teaching-learning-based optimization (TLBO) algorithm has been proposed to find the optimal level of machining variables for the performance measures. The optimal levels of cutting variables obtained through the algorithm are validated through confirmation test, predicting an error of 2.171 percentages between the computational and experimental results. The predicted result suggests that the proposed model can be used to select the ideal process states to achieve productivity for the cryo-treated EDM.
\end{abstract}

Keywords. EDM; electrode wear ratio; soaking duration; TOPSIS; TLBO.

\section{Introduction}

In today's manufacturing scenario, hard and difficult-tomachine materials, viz. composites and super-alloys, are extensively used in automotive, aerospace, chemical power generation, gas evacuation, surgical utensils for laboratories and other leading industries seeking productivity. However, it is hard to machine these materials with conventional machining processes to produce intricate part shapes within tight tolerances. Therefore, advanced machining processes like electrical discharge machining (EDM) is usually adopted for the purpose. The material evacuation technique in EDM is due to occurrence succession of spark discharges

*For correspondence in between the electrodes. Owing to succession of spark discharges, a little amount of material is frequently eroded from both the electrodes and the debris are removed by the flushing action of a dielectric fluid. In EDM, high erosion of tool has emerged as a major obstacle to achieve productivity. Past studies indicate that primarily copper and graphite electrodes may result in increasing productivity, but their usage is primarily restricted to rough machining conditions [1-4]. However, use of brass electrodes can produce high dimensional accuracy and surface finish but low material removal rate because of wearing of electrodes. In order to increase the wearing resistance of tool electrode, heat treatment process is typically adopted [5-7]. Cryogenic treatment is an inexpensive and everlasting process in which the entire material is kept in an isolated cryogenic 
chamber to be cooled down to a specific low temperature gradually, retained at the low temperature for some duration, returned to normal temperature gradually and finally heated to release the brittleness. The treatment fetches some noteworthy changes to the properties of the material, viz. enhancing the wear resistance, micro-hardness, thermal conductivity and refining the micro-structure [8]. Recently many studies reported the application of cryogenic treatment to enhance the wearing resistance of the tool and wire for non-conventional machining processes like EDM and wire EDM for machining of toughened and difficult-tomachine materials [9-12]. In cryogenic treatment, the variables that significantly affect the material properties are duration of soaking, soaking temperature, rate of cooling and heating rate [13]. Several studies reported that in cryogenic treatment, soaking duration of materials is an influential variable to enhance the material properties than other involved variables [8, 14-16]. However, studies to analyse the effect of soaking duration while machining in EDM with a relatively hard material like Inconel 718 with brass as the EDMed electrode material are very rare in the literature.

On the other hand the high wear ratio of electrode causes interruption during machining, thereby, enhancing machining cost and time, which in turn leads to low productivity of the process. To achieve productivity, the EDM operation should concentrate towards maximization of beneficial attributes, viz. material removal rate (MRR), accuracy of the drilled holes and tool life and minimization of non-beneficial attributes, viz. surface roughness, recast layer and tool wear. However, achieving all these primarily depends up on selection of optimal level of machining variables. Selection of optimal level of cutting variables helps in getting the desired performance measures. Or else, improper selection of cutting variables can lead to errorprone results, accidents during machining and damages to work-tool pair. Therefore, to achieve productivity, proper selection of cutting variables is vital. In a significant move to ehance productivity, researchers have attempted to implement nontraditional optimization techniques, viz. particle swarm optimization (PSO) and genetic algorithm (GA), to achieve the optimal level of cutting variables [17, 18]. However, applications of these algorithms are limited to use of constraints handling, penalty functions and proper controlling parameters, etc.

To address these issues, the present work attempts to study the consequences of deep cryo-treated $\left(-196^{\circ} \mathrm{C}\right)$ brass tools subjected to different soaking durations, viz. 0 , 24 and $36 \mathrm{~h}$, while machining with Inconel 718 work material. The study also analyses the effect of machining variables, viz. open-circuit voltage, discharge current, pulse-on time, duty factor and flushing pressure, on machining characteristics, viz. electrode wear ratio (EWR), surface quality and radial over-cut. Effects of soaking duration on machining performance of electrodes and workpieces are extensively studied through scanning electron microscope (SEM) micrographs and X-ray diffraction (XRD) analysis. The multiple performance measures are converted into an equivalent single performance measure by calculating the relative closeness coefficient by the TOPSIS approach. Meanwhile, non-linear regression analysis is conducted to develop a valid empirical model relating process variables and relative closeness coefficient. Finally, a novel TLBO algorithm has been proposed to find the optimal level of machining variables for the performance measures (relative closeness coefficient). The optimal levels of cutting variables obtained through the algorithm are validated through confirmation tests.

\section{Literature review}

Extensive study of past literature suggests that researchers have made ample efforts to enhance the machining performance of the EDM process in order to find the best parametric setting for achieving improved material removal rate and minimum tool erosion and surface roughness for a different combination of the work-tool pair. Prabhu and Vinayagam [19] have used fuzzy logic and grey relational analysis to find the optimum level of machining conditions while machining in the presence of carbon nano-tube particles for machining characteristics, viz. surface roughness and material evacuation. Taguchi's experimental architecture along with grey relational analysis is employed to obtain the best machining condition when AISI P20 steel is machined with copper tool material by Dewangan and Biswas [20]. El-Taweel and Hewidy [21] have recommended the use of a planetary EDM for achieving better surface finish and dimensional accuracy at reduced machining time. A few studies report parametric investigations on the proposed model followed by finding the best machining condition for the process while machining workpieces like AISI D2 steel, metal matrix and ceramic composite with copper electrode [22-24].

Many researchers have adopted controlled cryogenic cooling of tool and workpiece to achieve significant improvement in machining performance of the process. When such approaches are associated with cooling of tool and work material the conventional EDM process is termed as cryo-treated EDM. In this direction, Kumar et al [9] have studied the consequences of important variables in the presence of suspended graphite particles on performance measures, viz. wear ratio and TWR, while the Inconel 718 work material is eroded by means of cryogenically treated copper tool material. Jafferson and Hariharaan [10] have proposed a comparative study on machining efficiency of cryogenically treated and untreated micro-electrodes like those of copper, tungsten and brass while machining with an AISI 304 stainless-steel workpiece. It is observed that for tungsten electrode the tool wear is reduced up to $58 \%$ 
followed by those of brass and copper when electrodes are cryogenically cooled. Kapoor et al [11] found for cryogenically cooled brass wire that type of wire, time amid consecutive two pulses and wire tensions are the key process variables for material evacuation. Gill and Singh [13]. attempted machining cryogenically treated titanium alloy workpiece with copper electrode in an electric discharge machining process. It is observed that higher material removal rate (MRR) with precisely drilled holes and lower wear ratio can be achieved when the work material is cryogenically treated. Srivastava and Pandey [25] found that substantial reduction in electrode wear and surface irregularity with good surface integrity of tool can be achieved with a cryogenically treated copper tool on a machine M2 grade steel workpiece rather than an untreated copper tool. Abdulkareem et al [26] have analysed the influence of spark-off duration, discharge current, pulse-off time and open-circuit voltage on machining characteristics, viz. surface quality and electrode wear. They concluded that if the cryogenically cooled electrodes are employed during machining, the wear ratio can be reduced up to twenty-seven percentages. Ultrasonically assisted and cryogenically treated tool can be employed in the EDM process to enhance wear resistance and achieve better custody of tool profile as suggested by Srivastava and Pandey [27].

Several numerical and theoretical models have also been reported to study the process behaviour in EDM with a view to reduce the cost of experimentation. A few studies were proposed for precise and accurate prediction of responses, viz. material removal rate and TWR, using artificial intelligence techniques (AI), viz. artificial neural networks (ANN) and GA [28-30]. Chen and Mahdivian [31] have suggested a theoretical model to estimate the material removal rate and surface quality considering process variables like discharge current and pulse duration. Mohanty et al [32] have suggested a thermo-structural model based on finite-element approach for precise prediction of three responses, viz. MRR, TWR and residual stress.

It is observed that brass as EDM electrode possesses poor material removal rate and high wear ratio owing to its low thermal and mechanical properties. Hence, it is primarily applied in finishing operation as compared with copper and graphite tools [1, 3, 17, 33]. However, in order to achieve productivity it can be cryogenically cooled to enhance the wearing resistance and material evacuation abilities $[10,11]$. Hence, it is important to evaluate the machining efficiency of the process with cryogenically treated brass electrode against a difficult-to-machine material like Inconel 718.

A critical study of past literature on cryo-treated EDM reveals that past studies primarily focus on a particular duration of soaking during deep cryogenic treatment without justifying the purpose for the same [12, 25, 34]. It is also observed that the aspect of soaking duration and its outcomes on machining performance of the process have not been emphasized intensively in the literature. Further, the optimal process condition for simultaneous optimization of multiple performance characteristics for cryo-treated EDM is not adequately dealt with in the literature. Mostly researchers have adopted GA, PSO and fuzzy logics for achieving the best machining conditions of conventional EDM process. Even though many studies have been reported until now to find the optimal level of machining variables through non-traditional optimization techniques, no study has been reported to date that applies the efficient algorithm TLBO for solving a multi-objective problem. Hence, attempt must be made to find the optimal level of machining variables through a robust algorithm like TLBO.

Therefore, the present investigation aims at justifying the effectiveness of soaking duration by considering it as a process variable and measuring the performance measures of the EDM process. The multiple performance characteristics are converted to an equivalent single performance measure by calculating the relative closeness coefficient and are ranked according to preference order by TOPSIS approach. An evolutionary TLBO algorithm has been proposed to get the best relative closeness coefficient solution with the optimized process parameters. Finally, the optimal level of machining variables achieved through the method is validated by accomplishing the confirmative test.

\section{TOPSIS method}

TOPSIS is a multi-attribute decision-making approach (MADM) proposed by Huang and Yoon [35]. The method is simple in concept and involves little computational difficulty in comparison with other MADM techniques like utility concept, grey relational analysis and desirability function, etc. The approach chooses the best alternative that simultaneously has the least geometric distance from the positive ideal solution and extreme long geometric distance from the negative ideal solution. The performance characteristics are considered as attributes, whereas the nondominating solutions can be regarded as the alternatives. Attribute values must be numerically and monotonically increasing or decreasing for making use of this method. TOPSIS provides an important ranking for the attributes by considering full information from the attributes, and does not call for attribute preferences to be independent. The procedural steps for TOPSIS method is illustrated in the steps $1-5$ in the following lines $[36,37]$.

Step (1): The normalized decision value matrix is calculated from the original decision value matrix using Eq. (1):

$$
P_{i j}=\frac{x_{i j}}{\sqrt{\sum x_{i j}^{2}}} \text { for } i=1,2, \ldots m \text { and } j=1,2, \ldots n,
$$


where $x_{i j}$ and $P_{i j}$ are original and normalized decision value, respectively, $m$ is the number of alternatives (nondominating solutions) and $n$ is the number of performance measures (objectives or attributes).

Step (2): The weighted normalized decision value matrix is calculated using the weights for attributes selected by the decision maker as follows:

$$
V_{i j}=W_{j} P_{i j}
$$

where $V_{i j}$ is the weighted normalized decision value matrix and $W_{j}$ is the weight for the $j$ th objective value.

Step (3): The positive ideal and negative ideal solutions from the weighted normalized decision value matrix are recognized. The positive ideal and the negative ideal value solutions can be represented by the following equations: $A_{+}$ $=\left\{V_{1}^{+}, \ldots, V_{n}^{+}\right\}$where $A_{+}$is the positive ideal value solution and

$$
V_{j}^{+}= \begin{cases}\max \left(V_{i j}\right) & \text { if } j \in J \\ \min \left(V_{i j}\right) & \text { if } j \in J^{\prime}\end{cases}
$$

$A_{-}=\left\{V_{1}^{-}, \ldots, V_{n}^{-}\right\}$where $A_{-}$is the positive ideal value solution and

$$
V_{j}^{-}= \begin{cases}\min \left(V_{i j}\right) & \text { if } j \in J \\ \max \left(V_{i j}\right) & \text { if } j \in J^{\prime}\end{cases}
$$

where $\quad J=\{j=1,2, \ldots, n \mid j$ associated with benefit attribute $\}$

$J^{\prime}=\{j=1,2, \ldots, n \mid j$ associated with cost attribute $\}$.

Step (4): The separation measures for each alternative are estimated. The separation from the positive ideal value solution and the negative ideal value solution can be calculated using the following equation:

$S_{i}^{+}=\left[\sum\left(V_{j}^{+}-V_{i j}\right)^{2}\right]^{1 / 2}$ for $i=1,2, \ldots m$ and $j=1,2, \ldots n$,

where $S_{i}^{+}$is separation from the positive ideal solution.

$S_{i}^{-}=\left[\sum\left(V_{j}^{-}-V_{i j}\right)^{2}\right]^{1 / 2}$ for $i=1,2, \ldots m$ and $j=1,2, \ldots n$,

where $S_{i}^{-}$is separation from the negative ideal solution.

Step (5): The TOPSIS rank is calculated by estimating the relative closeness to the ideal value solution using the following equation:

$$
C_{i}^{+}=\frac{S_{i}^{-}}{\left(S_{i}^{+}+S_{i}^{-}\right)} \text {where } 0 \leq C_{i}^{+} \leq 1 .
$$

$C_{i}^{+}$is the relative closeness of the alternative.

The best solution is selected according to the preference rank order of $C_{j}^{+}$.

\section{TLBO approach}

Real-world problem involves a large number of complex process variables and contradictory performance measures. Thus, it is tough to find the global optimum solution for a highly complicated and nonlinear objective function. In order to overcome this difficulty, there is a vital need to propose an efficient and effective optimization technique that works on a continuous search domain. Recently, to solve these issues, many meta-heuristic and hybrid algorithms, viz. chemical reaction optimization combined with taboo search (CROTS), PSO, improved max-min ant system (IMMAS), ant colony optimization (ACO), etc. have been proposed by several researchers [38-41]. The objective behind proposing these algorithms is to achieve the global optimum solution in less computational effort and time. However, these algorithms have some constraints like proper selection of controlling variables, penalty functions, etc. To address these limitations, Rao and Savsani [42] proposed a novel optimization technique called TLBO. The specific advantage of this method is that it does not require any algorithmic variables. Due to simple concept, rapid convergence and easy implementation, TLBO finds extensive applications in many real-world manufacturing problems, viz. flow shop scheduling, power flow experiment problems, sterling heat engine, etc. [42-47].

The TLBO algorithm was originally motivated by teaching-learning process between a teacher and learners in the classroom and it was proposed by Rao et al [42-44, 48]. The effectiveness of the algorithm depends on the quality of influence of the teacher on the learners in a classroom. Thus teachers and learners are the key features of the algorithm, and hence the whole algorithm is divided into two essential parts, viz. (i) teacher phase and (ii) learner phase. A good teacher is treated as a learned person who can motivate and trains students to obtain better marks or grades. Likewise, the learners also enhance their knowledge by interacting with each other. The details of these two phases are described further.

\subsection{Teacher phase}

A teacher is actually referred to as a highly qualified personnel and he imparts knowledge among the learners (students). A good teacher always tries to improve the level of learners' up to his/her level. However, in actual practice, it is not possible, and a teacher can increase the normal mean $\left(M_{j}\right)$ of the class to a better value $\left(M_{\text {new }}\right)$. Thus the difference between existing mean and result and the improved mean result is given as

$$
\text { difference_mean }=r_{i}\left(M_{\text {new }}-T_{F} M_{j}\right)
$$

where $T_{F}$ is the teaching factor that decides the mean value and $r_{i}$ is a random number in the range $[0,1]$. The value of $T_{F}$ is decided randomly with equal probability: 


$$
T_{F}=\operatorname{round}[1+\operatorname{rand}(0,1)(2,1)] .
$$

This teaching factor is varied from 0 to 1 randomly, where 1 implies no transfer of knowledge while 2 implies complete transfer of knowledge with respect to the difference in mean. The existing solution is modified, and it is given by the relation

$$
X_{\text {new }, i}=X_{\text {old }, i}+\text { difference }- \text { mean }_{i} .
$$

\subsection{Learner phase}

The second half of the algorithm contains the learners where they can enhance their knowledge either by interacting with the teacher or by conversation with other learners. A learner can know a new material if another learner is more knowledgeable than him. Mathematically these phenomena can be expressed as follows.

At any iteration $I$, considering two different learners $X_{i}$ and $X_{j}$ where $i \neq j$

$$
\begin{aligned}
& X_{\text {new }, i}=X_{\text {old }, i}+r_{i}\left(x_{i}-x_{j}\right) \text { if } f\left(x_{i}\right)<f\left(x_{j}\right), \\
& X_{\text {new }, i}=X_{\text {old }, i}+r_{i}\left(x_{j}-x_{i}\right) \text { if } f\left(x_{j}\right)<f\left(x_{i}\right) .
\end{aligned}
$$

Figure 1 shows the flow chart for the TLBO algorithm.

\section{Experimental details}

In this work, a Box-Behnkin design of response surface approach is employed to conduct the experiments. The approach is very much suitable to plan the experiments and is quite capable of extracting maximum information from the study with minimum experimental runs by reducing the number of experiments [17]. As per the BoxBhenken design approach, fifty four experiments are to be conducted in order to analyse the consequences of discharge current, open-circuit voltage, duty factor, pulse-on time, flushing pressure and soaking duration on machining characteristics, viz. EWR, surface roughness $\left(R_{a}\right)$ and radial over-cut $(C)$. Duty factor can be defined as the ratio of duration of spark to total spark time, and mathematically, denoted as tau $\tau=\frac{T_{o n}}{T_{o n}+T_{o f f}}$. Generally it is expressed in terms of percentage, where $T_{\text {off }}$ is the pulse-off-time and $T_{o n}$ is the duration of spark. The parametric limits are coded using Eq. (13):

$$
\text { Coded value }(\mathrm{Y})=\frac{A-\frac{A_{\max }-A_{\min }}{2}}{\frac{A_{\max }-A_{\min }}{2}}
$$

where $Y$ is coded value $(-1,0,1), A_{\max }, A_{\min }$ are, respectively, upper and lower limits of actual variables and $A$ is the actual value of the corresponding variable. The process variables and their levels are shown in table 1.
The experiments for the study are conducted in a die sinking CNC EDM machine, namely ECOWIN PS 50ZNC, which uses paraffin oil as the dielectric for flushing debris with side flushing and positive polarity. Inconel alloy 718, a nickel-chromium alloy, which possess high strength, corrosion resistance and good tensile strength having extensive industrial applications is used as the work material. It is an aerospace material and has extensive application in fabrication of parts, viz. aircraft body, liquid fueled rockets, engine parts for gas turbine, cryogenic container clasps, etc. The thermal properties and chemical structure of the workpiece are provided in table 2 . In a machining operation, the tool material is an important aspect as it straightaway influences the cost of machining expenses. Therefore, because of its poor mechanical properties and melting point, brass has been selected as the electrode material. The objective behind choosing brass as the tool material is to enhance its thermal and electrical conductivity by virtue of cryogenic cooling and make it suitable to meet the industrial requirements. The required tool materials are prepared from three different brass rods that are of $20 \mathrm{~mm}$ diameter and $70 \mathrm{~mm}$ length. For suitability during machining, the diameter of tool material is machined to $13.5 \mathrm{~mm}$ in a lathe machine. A surface roughness tester manufactured by Mitutoya Surftest, SJ 210, is used to measure the surface roughness of the work material on the machined surface. The crater dimension on the work material surface is measured using a tool makers microscope manufactured by the Carl Zeiss company.

The cryogenic treatment is conducted under dry conditions where the tool is not directly exposed to the liquid nitrogen with an objective to avoid thermal shock of sudden decrease of temperature. A cryo-freezer Kryo 560-16 shown in figure 2 is used for the treatment of the brass electrodes. The freezer is made up of a treatment housing attached with a liquid nitrogen tank. A circular channel connects the chamber with the tank. A solenoid valve with the help of a programmable digital temperature controller controls the flow of liquid nitrogen into the freezer. Liquid nitrogen from the tank flows into the circular channel and crosses the threshold into the freezer in the vapour state by the control valve. The cryogenic treatment variables, viz. soaking duration, cryogenic temperature, rate of cooling and rate of heating, are governed by the programmable digital temperature controller. To begin with, one of the electrode materials is kept inside the cryogenic chamber, and is gradually cooled up to the temperature of $-196^{\circ} \mathrm{C}$ at $1^{\circ} \mathrm{C} / \mathrm{min}$. The material is held at this temperature for $24 \mathrm{~h}$ and gradually brought back to room temperature at the rate of $1^{\circ} \mathrm{C} / \mathrm{min}$. Thereafter, the material is exposed to a twostage heating process for dissipating the stresses induced at cryogenic cooling. This process is accomplished by raising the temperature up to $+196^{\circ} \mathrm{C}$ slowly and then gently conveying back to the normal temperature. A similar method of cryogenic treatment is considered for the second 


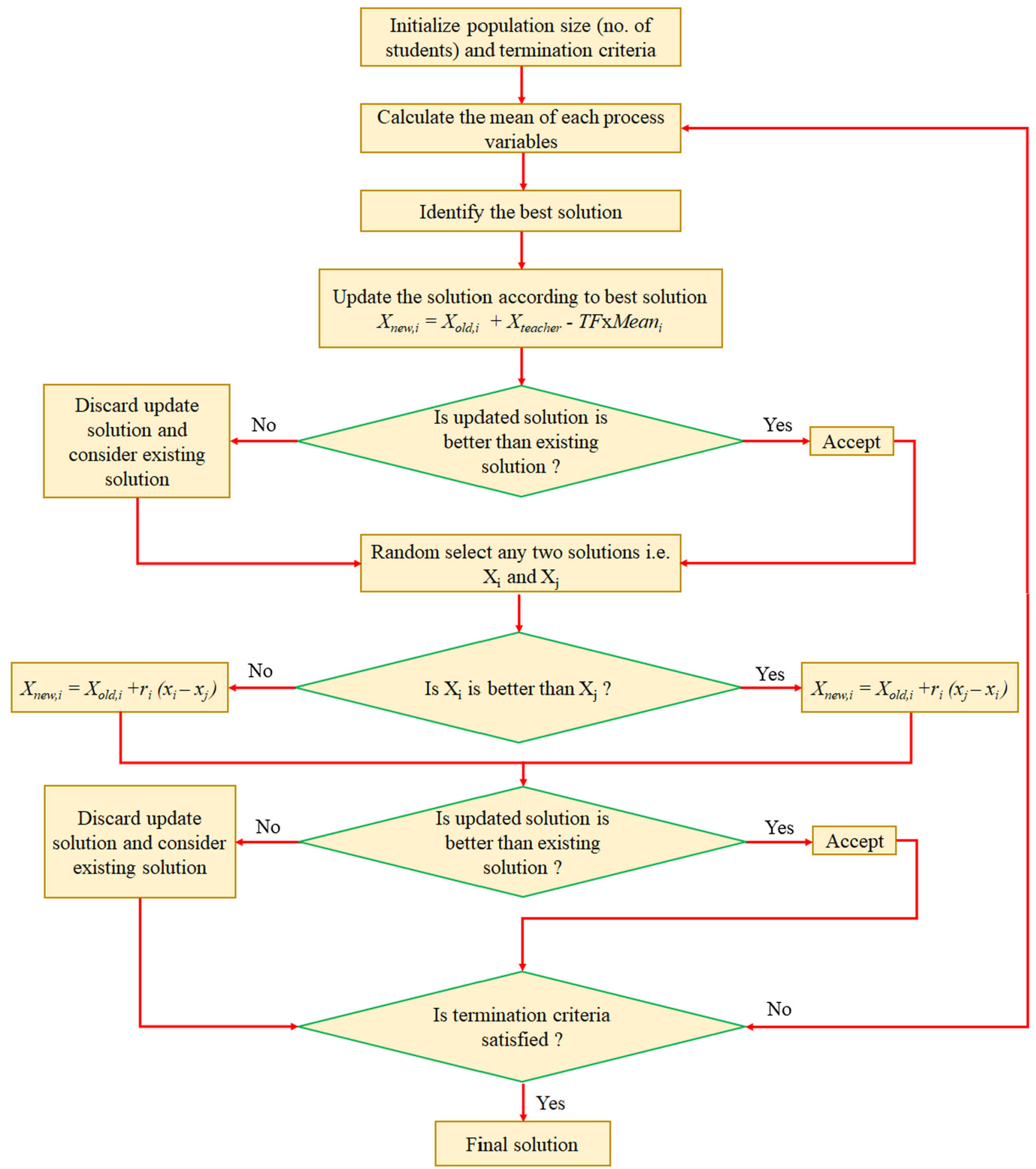

Figure 1. Flow chart for TLBO algorithm.

tool material except that the soaking duration is $36 \mathrm{~h}$ rather than $24 \mathrm{~h}$. The third tool material is left untreated. A graphical explanation of cryogenic cooling and two-stage heating process for both the cycles performed in this work is shown in figure 3 . To measure the thermal conductivity of the material, a thermal conductivity tester Unitherm TM 2022 is used in this study. A Vaiseshika micro-hardness tester is used to measure the micro-hardness of the material. The properties of the tool before and after cryogenic treatment are presented in table 3 . From the table it can be 
Table 1. Process variables and their levels [49].

\begin{tabular}{lcccc}
\hline & \multicolumn{4}{c}{ Levels } \\
\cline { 2 - 5 } Process variables & Symbols & -1 & 0 & 1 \\
\hline Open-circuit voltage (V) & $A$ & 70 & 80 & 90 \\
Discharge current (A) & $B$ & 3 & 5 & 7 \\
Pulse-on time (s) & $C$ & 100 & 200 & 300 \\
Duty factor (\%) & $D$ & 80 & 85 & 90 \\
Flushing pressure (bar) & $E$ & 0.2 & 0.3 & 0.4 \\
Cryogenic treatment & $F$ & 0 & 24 & 36 \\
$\quad$ soaking duration (h) & & & & \\
\hline
\end{tabular}

observed that treated samples with longer soaking duration possess the highest value of micro-hardness in comparison with the other two samples (i.e., untreated sample and 24-h soaking duration sample) due to longer duration of soaking. Due to longer duration of soaking the grain size is reduced and particles come very close to each other. As a result, the grain structure gets dense and micro-structure is refined. This in turn influences increase in micro-hardness and thermal conductivity.

\section{Micro-structural analysis and XRD analysis}

An optical microscope (Olympus model no-BX-5175E21P, Japan) is used to investigate the micro-structural changes that occur on the brass samples before and after cryogenic treatment. The optical micrograph photographs for the untreated and treated brass specimens at $400 \times$ enlargement have been given in figure 4(a)-(c). From the photographs, it can be distinctly seen that in the untreated samples the grains are larger and irregular in size and scattered, but samples treated with soaking for $24 \mathrm{~h}$ show distinct grain boundaries with average grain size smaller in size than that of untreated samples. On the other hand, samples treated for longer soaking duration, i.e., up to $36 \mathrm{~h}$, have more refined and denser grains. It is also visible that the average grain size is smaller in comparison with other two samples due to the longer soaking duration of soaking.

Figure 4(a)-(c) shows micro-structures of three electrode samples used in the study. XRD analysis is also performed for the treated brass samples in order to compare the results obtained by the optical micrographs images. An X-ray diffractometer (model no-X-Pert PRO, PANalytical) made in the Netherlands is employed for the XRD analysis and the regular grain size is estimated by means of the DebyeScherrer equation and is given by

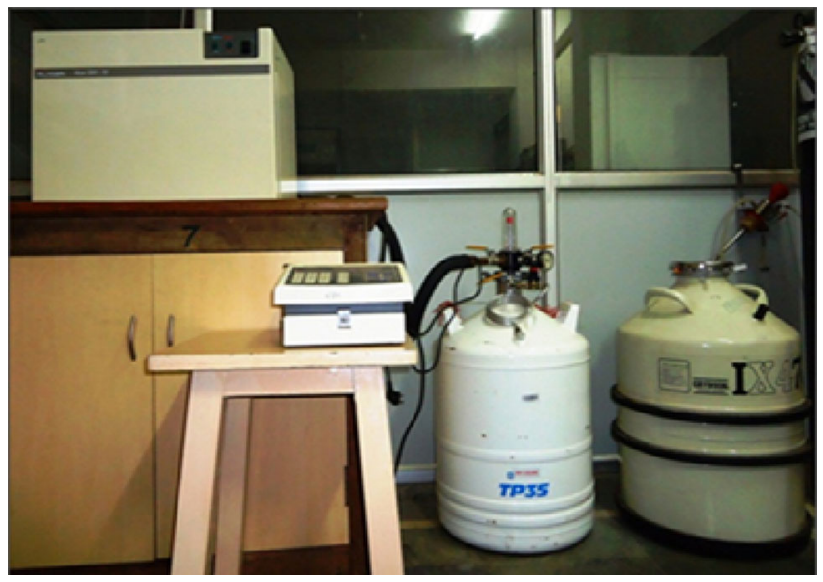

Figure 2. PLANER Kryo 560-16 cryogenic freezer.

$$
G S=\frac{0.89 \alpha}{\beta \cos \theta}
$$

where $G S$ is the grain size in nanometer, $\alpha$ is the wavelength of X-ray used in the study, $\beta$ is the line broadening at half the maximum intensity (FWHM) in radians in the $2 \theta$ scale and $\theta$ is the Bragg angle in the study. The estimated values of the regular grain size have been presented in table 3 .

The XRD analysis report revealed that due to deep cryogenic cooling the average grain size of the samples treated for $24 \mathrm{~h}$ soaking duration was decreased up to $7.78 \%$ when compared with the untreated samples. However, when compared with the same, a significant decrease of $25.43 \%$ average grain size is observed for the samples treated for 36-h soaking duration. This result is analogous to the result obtained through the micro-structural investigations.

\section{Calculation of performance measures}

Inconel 718 rectangular plates of dimensions $5 \times 105 \times 110 \mathrm{~mm}^{3}$ machined on the EDM machine ECOWIN PS 50ZNC with three different brass electrodes for $20 \mathrm{~min}$ have been shown in figure 5. After completion of every experiment, an accurate electronic weight balance is employed for quantifying the weights of the workpiece and tool material before and after machining.

The weight of workpiece and tool material before and after machining is noted down to estimate EWR in percentage using the equations

Table 2. Thermal properties of the work material Inconel 718 [49].

\begin{tabular}{lccccc}
\hline Properties & Density & Melting temperature & Thermal conductivity & Thermal expansion & Poisson's ratio \\
\hline Value & $8190 \mathrm{~kg} / \mathrm{m}^{3}$ & $1609 \mathrm{~K}$ & $15 \mathrm{~W} / \mathrm{m} \mathrm{K}$ & $13.0 \mu \mathrm{m} / \mathrm{m}^{\circ} \mathrm{C}$ & $0.27-0.3$ \\
\hline
\end{tabular}




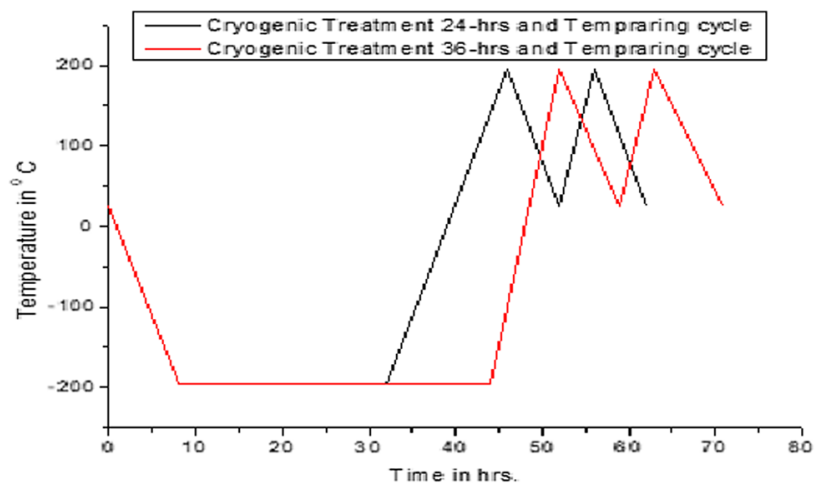

Figure 3. Cryogenic treatment and two-stage tampering process shown graphically.

Table 3. Properties of brass samples before and after cryogenic treatment [49].

\begin{tabular}{lcccc}
\hline & & & $\begin{array}{c}\text { Treated } \\
\text { with } \\
\text { soaking } \\
\text { for } 24 \mathrm{~h}\end{array}$ & $\begin{array}{c}\text { Treated } \\
\text { with } \\
\text { soaking } \\
\text { for } 36 \mathrm{~h}\end{array}$ \\
\hline $\begin{array}{c}\mathrm{Cu} 62 \% \mathrm{Zn} \\
38 \%\end{array}$ & $\begin{array}{c}\text { Thermal } \\
\text { conductivity } \\
\text { (W/m K) } \\
\text { Micro-hardness } \\
\text { (VHN) } \\
\text { Average grain } \\
\text { size (nm) }\end{array}$ & 108 & 121 & 129 \\
& 143.72 & 132.38 & 111.64 \\
\hline
\end{tabular}

$$
\begin{aligned}
M R R & =\frac{1000 \Delta W w}{\rho_{w} T} \\
T W R & =\frac{1000 \Delta W t}{\rho_{t} T}
\end{aligned}
$$

$$
E W R=\frac{100 T W R}{M R R}
$$

where $M R R$ is the material removal rate in $\mathrm{mm}^{3} / \mathrm{min}, \Delta W$ is the weight loss due to machining for workpiece and $\rho_{w}$ is the workpiece density. TWR is the tool wear rate in $\mathrm{mm}^{3}$ / $\min , \Delta W t$, is the weight loss of tool material due to machining, $\rho_{t}$ is the tool density, i.e., $\rho_{\text {brass }}=8565 \mathrm{~kg} / \mathrm{m}^{3}$ and $T$ is the time taken for machining. The surface roughness measurement on the work material surface is measured with a surface roughness tester Surftest SJ 210, Mitutoyo. Five readings on the traverse directions of the workpiece are measured, and the average of the five readings is recorded.

The difference between electrode diameter and the maximum diameter of the machined cavity is called as radial over-cut and is measured using the following relation:

$$
R O C=\frac{d_{w}-d_{t}}{2}
$$

where $d_{w}$ and $d_{t}$ are the extreme diameter of the cavity and diameter of the tool, respectively. Table 4 shows the BoxBehnken experimental architecture in conjunction with estimated machining characteristics. The last column shows the relative closeness coefficient calculated by the TOPSIS method.

\section{Results and discussion}

In all, 54 experiments were conducted to analyse the effects of imprortant process variables and analysis of variance (ANOVA) was carried out for each machining characteristic. Importance of each variable on the performance measures is detected at the importance level of 0.05. The ANOVA for EWR along with the contribution of each

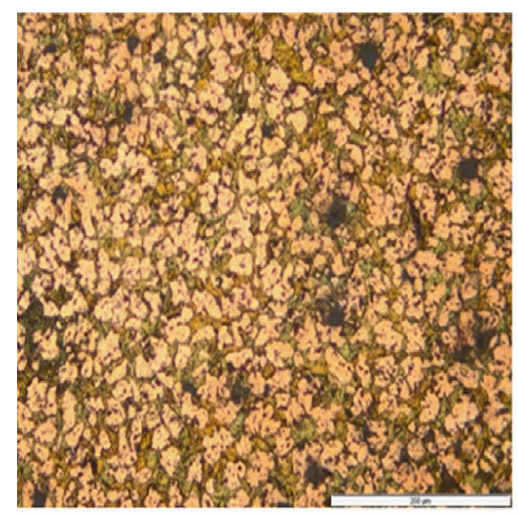

(a) Untreated brass

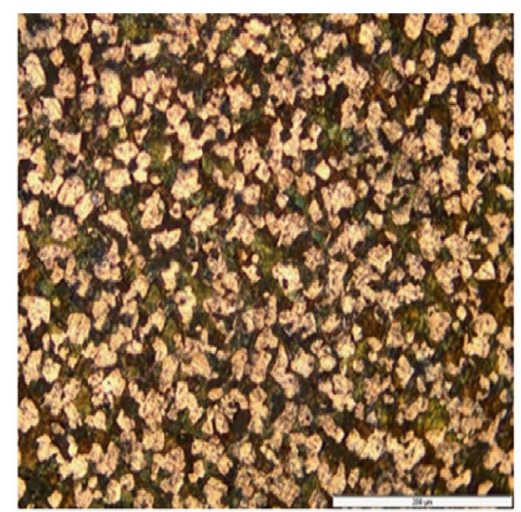

(b) Cryogenic-treated brass with soaking duration 24-hrs

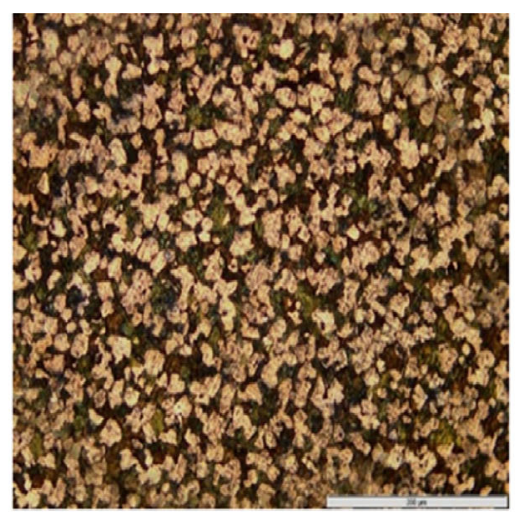

(c) Cryogenic-treated brass with soaking duration 36 -hrs

Figure 4. (a)-(c) Optical micrograph images of three electrode samples used in the study. 


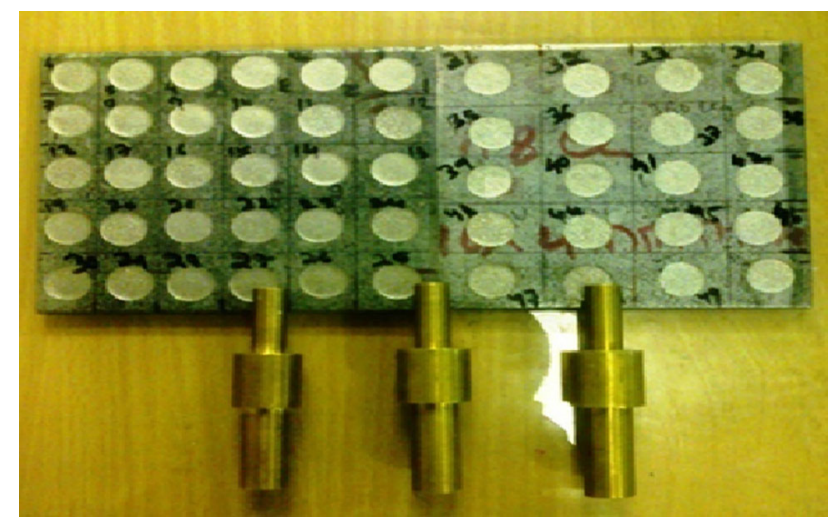

Figure 5. Three tool materials with Inconel 718 workpiece after machining.

variable is shown in table 5. The table shows that at the importance level of 0.5 , open-circuit voltage, discharge current, pulse-on time, duty factor, soaking duration, combined effect of discharge current-soaking duration and duty factor-flushing pressure and dual effect of discharge current, pulse-on time, duty factor and soaking duration are the vital input variables. Moreover, it indicates that soaking duration is the most dominant process variable for EWR with a contribution of $78.35 \%$. The table also shows that discharge current, pulse-on time, duty factor and opencircuit voltage are the other influential variables with the contribution of $10.66 \%, 2.13 \%, 1.04 \%$ and $0.64 \%$, respectively. It is observed that the lack of fit is insignificant for EWR; also, the coefficient of determination $\left(R^{2}\right)$ and adjusted $\left(R^{2}\right)$ values are found to be quite large, i.e., up to $98.9 \%$ and $98.4 \%$, respectively.

Likewise, from the ANOVA table of surface roughness it is observed that at the significance level of 0.5 , discharge current, pulse-on time, duty factor, soaking duration, combined effect of pulse-on time-soaking duration and dual effect of open-circuit voltage, pulse-on time and soaking duration are critical process variables. The table indicates that soaking duration is the greatest dominant variable for surface roughness with a contribution of $58.99 \%$. It is also observed that discharge current, pulse-on time and duty factor are the other influential variables with a contribution of $18.60 \%, 9.62 \%$ and $0.39 \%$, respectively. It is observed that the lack of fit is insignificant for surface roughness along with the coefficient of determination $\left(R^{2}\right)$, and adjusted $\left(R^{2}\right)$ values are found to be quite large at $96.1 \%$ and $94.1 \%$, respectively. Similarly, the ANOVA for radial over-cut shows that at the significance level of 0.5 , discharge current, pulse-on time, duty factor, soaking duration, combined effect of discharge current-soaking duration and dual effect of open-circuit voltage and soaking duration are the key variables. For radial over-cut, soaking duration is found to be the most dominant variable with a contribution of $79.01 \%$. The other influential variables are discharge current, pulse-on time and duty factor with a contribution of $8.88 \%, 2.83 \%$ and $1.18 \%$, respectively. It is observed that the lack of fit is found to be insignificant for radial over-cut and the coefficient of determination $\left(R^{2}\right)$ and adjusted $\left(R^{2}\right)$ values are found to be quite large, i.e., up to $97.5 \%$ and $96.6 \%$, respectively. Flushing pressure has little effect on the performance measures.

Table 6 shows the ANOVA for relative closeness coefficient with the percentage contribution of each variable after elimination of insignificant variables. The table shows that soaking duration is the most influential variable with a contribution of $79.06 \%$ followed by discharge current, pulse-on time and duty factor with a contribution of $10.52 \%, 3.25 \%$ and $1.06 \%$, respectively. The table also shows that square terms of soaking duration and open-circuit voltage and interaction term discharge current and tool exhibit a significant effect on relative closeness coefficient. Open-circuit voltage and flushing pressure are found to be not significant for relative closeness coefficient.

After completion of 54 experimental runs the machined surface of the tool tip is investigated with the SEM ModelJEOL JSM-6084LV at $100 \times$ magnification. The micrographs images are shown in figure 6(a)-(c). It is clearly evident from the photographs that for the untreated electrode, the machined surface area is severely damaged due to higher melting and vaporization from electrode tip. The tool treated for 24-h soaking duration shows good retention of machined surface due to less melting of the electrode material from the tip. However, tools treated with longerduration soaking, i.e., up to $36 \mathrm{~h}$, exhibit the best performance with respect to initial shape retention and better surface integrity due to the least evaporation and melting of material among the three tools.

The SEM micrographs taken for the machining conditions of $80 \mathrm{~V} / 5 \mathrm{~A} / 300 \mu \mathrm{s} / 80 \% / 0.2 \mathrm{bar} / 0 \mathrm{~h}$ and $80 \mathrm{~V} / 5$ $\mathrm{A} / 300 \mu \mathrm{s} / 80 \% / 0.2 \mathrm{bar} / 36 \mathrm{~h}$ are shown in figure $7(\mathrm{a})$ and (b), respectively. These micrographs show that the surface quality of the machined surface increases considerably as the micro-cracks and pores disappear from the machined surface due to increase in soaking duration. Therefore, it is concluded that machined surface quality is primarily influenced by the accurate retention of tool shape and cryogenically treated tool; longer soaking duration creates finer surface quality due to proper shape retention and uniform sparking on the machined surface.

The machining cost and time of EDM process are largely influenced by EWR. Hence, it is an important performance measure. The surface plot of EWR with soaking duration and discharge current is shown in figure 8. From the figure it can be observed that EWR increases rapidly with increases in discharge current at the lower level of soaking duration. Increase in discharge current leads to substantial enhancement in spark energy. As a result the volume of the molten material from both the electrodes increases, causing an increase in EWR. The figure also indicates that EWR varies inversely with increase in soaking duration. This is 
Table 4. Box-Behnken experimental design with estimated performance measures [49].

\begin{tabular}{|c|c|c|c|c|c|c|c|c|c|c|}
\hline Run order & $A$ & $B$ & $C$ & $D$ & $E$ & $F$ & EWR $(\%)$ & Surface roughness $\mathrm{m}$ & Radial over-cut (mm) & Relative closeness $C_{i}^{+}$ \\
\hline 1 & -1 & -1 & 0 & -1 & 0 & 0 & 92.12 & 8.4 & 0.145 & 0.774106 \\
\hline 2 & 1 & -1 & 0 & -1 & 0 & 0 & 97.03 & 8.43 & 0.135 & 0.777975 \\
\hline 3 & -1 & 1 & 0 & -1 & 0 & 0 & 119.1 & 9.5 & 0.25 & 0.563 .63 \\
\hline 4 & 1 & 1 & 0 & -1 & 0 & 0 & 123.2 & 9.7 & 0.244 & 0.562486 \\
\hline 5 & -1 & -1 & 0 & 1 & 0 & 0 & 99.3 & 8.6 & 0.19 & 0.695281 \\
\hline 6 & 1 & -1 & 0 & 1 & 0 & 0 & 105.21 & 8.67 & 0.195 & 0.677443 \\
\hline 7 & -1 & 1 & 0 & 1 & 0 & 0 & 125.15 & 9.75 & 0.28 & 0.506569 \\
\hline 8 & 1 & 1 & 0 & 1 & 0 & 0 & 129.4 & 10.2 & 0.27 & 0.508609 \\
\hline 9 & 0 & -1 & -1 & 0 & -1 & 0 & 89.31 & 7.9 & 0.144 & 0.789585 \\
\hline 10 & 0 & 1 & -1 & 0 & -1 & 0 & 118.26 & 9.6 & 0.259 & 0.549555 \\
\hline 11 & 0 & -1 & 1 & 0 & -1 & 0 & 105.19 & 9.5 & 0.24 & 0.598078 \\
\hline 12 & 0 & 1 & 1 & 0 & -1 & 0 & 130.09 & 11.3 & 0.34 & 0.387864 \\
\hline 13 & 0 & -1 & -1 & 0 & 1 & 0 & 91.43 & 8.2 & 0.149 & 0.773586 \\
\hline 14 & 0 & 1 & -1 & 0 & 1 & 0 & 121.37 & 9.75 & 0.249 & 0.557232 \\
\hline 15 & 0 & -1 & 1 & 0 & 1 & 0 & 110.29 & 9.3 & 0.25 & 0.579165 \\
\hline 16 & 0 & 1 & 1 & 0 & 1 & 0 & 130.19 & 10.2 & 0.35 & 0.387954 \\
\hline 17 & 0 & 0 & -1 & -1 & 0 & -1 & 132.18 & 10.3 & 0.39 & 0.323109 \\
\hline 18 & 0 & 0 & 1 & -1 & 0 & -1 & 136.17 & 11.9 & 0.47 & 0.171543 \\
\hline 19 & 0 & 0 & -1 & 1 & 0 & -1 & 142.36 & 10.6 & 0.45 & 0.216735 \\
\hline 20 & 0 & 0 & 1 & 1 & 0 & -1 & 145.4 & 12.5 & 0.52 & 0.074505 \\
\hline 21 & 0 & 0 & -1 & -1 & 0 & 1 & 73312 & 7.7 & 0.07 & 0.914317 \\
\hline 22 & 0 & 0 & 1 & -1 & 0 & 1 & 85.33 & 8.9 & 0.105 & 0.822364 \\
\hline 23 & 0 & 0 & -1 & 1 & 0 & 1 & 79.26 & 7.9 & 0.085 & 0.883558 \\
\hline 24 & 0 & 0 & 1 & 1 & 0 & 1 & 86.41 & 8.9 & 0.15 & 0.764901 \\
\hline 25 & -1 & 0 & 0 & -1 & -1 & 0 & 111.1 & 9.1 & 0.21 & 0.639378 \\
\hline 26 & 1 & 0 & 0 & -1 & -1 & 0 & 115.23 & 9.2 & 0.19 & 0.658345 \\
\hline 27 & -1 & 0 & 0 & 1 & -1 & 0 & 125.12 & 9.4 & 0.25 & 0.555692 \\
\hline 28 & 1 & 0 & 0 & 1 & -1 & 0 & 131.05 & 9.53 & 0.254 & 0.542027 \\
\hline 29 & -1 & 0 & 0 & -1 & 1 & 0 & 115.44 & 9 & 0.22 & 0.619792 \\
\hline 30 & 1 & 0 & 0 & -1 & 1 & 0 & 121.37 & 8.95 & 0.19 & 0.651567 \\
\hline 31 & -1 & 0 & 0 & 1 & 1 & 0 & 111.17 & 9.15 & 0.235 & 0.60238 \\
\hline 32 & 1 & 0 & 0 & 1 & 1 & 0 & 128.08 & 9.23 & 0.22 & 0.595653 \\
\hline 33 & 0 & -1 & 0 & 0 & -1 & -1 & 127.06 & 8.9 & 0.39 & 0.355156 \\
\hline 34 & 0 & 1 & 0 & 0 & -1 & -1 & 152.42 & 12.2 & 0.54 & 0.04192 \\
\hline 35 & 0 & -1 & 0 & 0 & 1 & -1 & 130.19 & 9.3 & 0.36 & 0.387648 \\
\hline 36 & 0 & 1 & 0 & 0 & 1 & -1 & 150.11 & 12.35 & 0.56 & 0.01937 \\
\hline 37 & 0 & -1 & 0 & 0 & -1 & 1 & 69.13 & 6.3 & 0.07 & 0.951802 \\
\hline 38 & 0 & 1 & 0 & 0 & -1 & 1 & 79.23 & 8.5 & 0.14 & 0.796543 \\
\hline 39 & 0 & -1 & 0 & 0 & 1 & 1 & 67.32 & 6.35 & 0.042 & 0.997541 \\
\hline 40 & 0 & 1 & 0 & 0 & 1 & 1 & 82.06 & 8.7 & 0.14 & 0.788693 \\
\hline 41 & -1 & 0 & -1 & 0 & 0 & -1 & 135.37 & 11.1 & 0.39 & 0.307187 \\
\hline 42 & 1 & 0 & -1 & 0 & 0 & -1 & 141.39 & 10.9 & 0.34 & 0.380721 \\
\hline 43 & -1 & 0 & 1 & 0 & 0 & -1 & 145.42 & 12.7 & 0.369 & 0.314291 \\
\hline 44 & 1 & 0 & 1 & 0 & 0 & -1 & 148.45 & 12.6 & 0.359 & 0.327894 \\
\hline 45 & -1 & 0 & -1 & 0 & 0 & 1 & 71.16 & 7.9 & 0.09 & 0.886796 \\
\hline 46 & 1 & 0 & -1 & 0 & 0 & 1 & 73.13 & 7.7 & 0.06 & 0.922814 \\
\hline 47 & -1 & 0 & 1 & 0 & 0 & 1 & 82.14 & 8.9 & 0.14 & 0.78374 \\
\hline 48 & 1 & 0 & 1 & 0 & 0 & 1 & 87.3 & 8.6 & 0.13 & 0.79741 \\
\hline 49 & 0 & 0 & 0 & 0 & 0 & 0 & 125.03 & 8.75 & 0.245 & 0.572724 \\
\hline 50 & 0 & 0 & 0 & 0 & 0 & 0 & 121.42 & 8.35 & 0.195 & 0.653914 \\
\hline 51 & 0 & 0 & 0 & 0 & 0 & 0 & 127.43 & 9 & 0.255 & 0.551105 \\
\hline 52 & 0 & 0 & 0 & 0 & 0 & 0 & 123.23 & 8.4 & 0.2 & 0.643224 \\
\hline 53 & 0 & 0 & 0 & 0 & 0 & 0 & 126.5 & 8.9 & 0.25 & 0.561137 \\
\hline 54 & 0 & 0 & 0 & 0 & 0 & 0 & 122.7 & 8.5 & 0.21 & 0.629191 \\
\hline
\end{tabular}


Table 5. ANOVA for EWR [49].

\begin{tabular}{|c|c|c|c|c|c|c|c|}
\hline Source & $\begin{array}{l}\text { Sum of } \\
\text { squares }\end{array}$ & $\begin{array}{l}\text { Degree of } \\
\text { freedom }\end{array}$ & $\begin{array}{l}\text { Mean } \\
\text { square }\end{array}$ & $F$ value & $\begin{array}{c}p \text {-value prob }> \\
F\end{array}$ & & $\begin{array}{c}\text { Contribution } \\
(\%)\end{array}$ \\
\hline Model & 29660.1 & 19 & 1561.06 & 162.8 & $<0.0001$ & Significant & \\
\hline $\begin{array}{l}A \text { - open-circuit } \\
\text { voltage }\end{array}$ & 194.09 & 1 & 194.09 & 20.24 & $<0.0001$ & & 0.65 \\
\hline$B$-discharge current & 3197.04 & 1 & 3197.04 & 333.42 & $<0.0001$ & & 10.66 \\
\hline$C$-pulse-on time & 641.08 & 1 & 641.08 & 66.86 & $<0.0001$ & & 2.14 \\
\hline$D$ —duty factor & 311.9 & 1 & 311.9 & 32.53 & $<0.0001$ & & 1.04 \\
\hline$E$-flushing pressure & 1.42 & 1 & 1.42 & 0.15 & 0.7031 & & 0.00 \\
\hline$F$-soaking duration & 23495.7 & 1 & 23495.7 & 2450.39 & $<0.0001$ & & 78.36 \\
\hline$A \times D$ & 12.13 & 1 & 12.13 & 1.26 & 0.2686 & & 0.04 \\
\hline$A \times E$ & 20.42 & 1 & 20.42 & 2.13 & 0.1537 & & 0.07 \\
\hline$B \times C$ & 24.82 & 1 & 24.82 & 2.59 & 0.1169 & & 0.08 \\
\hline$B \times F$ & 52.22 & 1 & 52.22 & 5.45 & 0.0257 & & 0.17 \\
\hline$C \times D$ & 4.52 & 1 & 4.52 & 0.47 & 0.4972 & & 0.02 \\
\hline$C \times F$ & 25.93 & 1 & 25.93 & 2.7 & 0.1093 & & 0.09 \\
\hline$D \times E$ & 93.84 & 1 & 93.84 & 9.79 & 0.0036 & & 0.31 \\
\hline$D \times F$ & 18.57 & 1 & 18.57 & 1.94 & 0.173 & & 0.06 \\
\hline$A^{2}$ & 38.68 & 1 & 38.68 & 4.03 & 0.0526 & & 0.13 \\
\hline$B^{2}$ & 850.93 & 1 & 850.93 & 88.74 & $<0.0001$ & & 2.84 \\
\hline$C^{2}$ & 129.52 & 1 & 129.52 & 13.51 & 0.0008 & & 0.43 \\
\hline$D^{2}$ & 62.28 & 1 & 62.28 & 6.5 & 0.0155 & & 0.21 \\
\hline$F^{2}$ & 730.06 & 1 & 730.06 & 76.14 & $<0.0001$ & & 2.43 \\
\hline Residual & 326.01 & 34 & 9.59 & & & & 0.65 \\
\hline Lack of fit & 298.88 & 29 & 10.31 & 1.9 & 0.2457 & $\begin{array}{c}\text { Not } \\
\text { significant }\end{array}$ & \\
\hline Pure error & 27.13 & 5 & 5.43 & & & & \\
\hline Cor total & 29986.1 & 53 & & & & & \\
\hline
\end{tabular}

because when a material is cryogenically treated, the electrons of the material can move freely inside the metal due to good molecular bonding. This allows increase in electrical conductivity of the material. Increase in electrical conductivity directly increases the thermal conductivity of the material as per the Wiedemann-Franz-Lorenz Law. Due to increase in thermal conductivity the local temperature rise of the material decreases owing to faster heat transfer away from the surface of the metal, which in turn declines tool wear. Owing to increase in soaking duration, the wearing resistance property of tool increases due to enhancement in thermal conductivity and micro-hardness. The heat rejection ability of the tools rises due to increase in thermal conductivity, which in turn causes decay of TWR and hence EWR is reduced. As per the micro-structural investigations, further increase in soaking duration, i.e., up to $36 \mathrm{~h}$, significantly decreases the grain size of the electrodes. As a result the micro-structure becomes refined and denser, leading to a substantial increase in microhardness of the material. Therefore, the opposing wearing resistance against the penetration of heat for the treated tools with longer soaking duration is increased. This phenomenon considerably reduces the evaporation and melting of material in treated tools and thus EWR at higher value soaking duration is reduced.
Likewise, the surface plot of EWR with duty factor and pulse-on time indicates that initially EWR shows an increasing trend with increase in pulse-on time but shows a decreasing trend at higher pulse duration. As the pulse-on time increases the duration of spark increases. However, for a particular duty factor, increasing pulse-on time decreases the number of sparks per unit time, which in turn reduces the spark density on the machining spot and hence reduces the electrode wear at higher pulse-on time. One more justification for lower wear of electrodes at higher pulse-on time is the sticking of carbon elements over the machined surface of both the electrodes, causing an improvement in the wearing resistance of tool and in turn declining EWR. The figure also reveals that EWR increases with increase in the duty factor owing to increase in number of sparks per unit time. Similarly, the surface plot of EWR with opencircuit voltage and duty factor indicates that EWR shows an increasing trend with increase in open-circuit voltage and duty factor due to increase in spark energy.

The surface plot of surface roughness with soaking duration and discharge current is shown in figure 9. From the figure it can observed that surface quality deteriorates heavily with an increase in discharge current at the lower level of soaking duration. The spark energy across the electrodes increases rapidly due to increase in discharge 
Table 6. ANOVA for relative closeness coefficient.

\begin{tabular}{|c|c|c|c|c|c|c|c|}
\hline Source & $\begin{array}{l}\text { Sum of } \\
\text { squares }\end{array}$ & $\begin{array}{l}\text { Degree of } \\
\text { freedom }\end{array}$ & $\begin{array}{l}\text { Mean } \\
\text { square }\end{array}$ & $F$ value & $\begin{array}{c}p \text {-value Prob }> \\
F\end{array}$ & & $\begin{array}{c}\text { Contribution } \\
(\%)\end{array}$ \\
\hline Model & 2.789364 & 15 & 0.185958 & 99.800 & $<0.0001$ & Significant & \\
\hline $\begin{array}{l}A \text {-open-circuit } \\
\text { voltage }\end{array}$ & 0.000997 & 1 & 0.000997 & 0.53495 & 0.4690 & & 0.034 \\
\hline$B$-discharge current & 0.300946 & 1 & 0.300946 & 161.513 & $<0.0001$ & & 10.52 \\
\hline$C$-pulse-on time & 0.093187 & 1 & 0.093187 & 50.0119 & $<0.0001$ & & 3.258 \\
\hline$D$-duty factor & 0.030437 & 1 & 0.030437 & 16.335 & 0.0002 & & 1.064 \\
\hline$E$-flushing pressure & 0.000373 & 1 & 0.000373 & 0.200 & 0.6570 & & 0.013 \\
\hline$F$-soaking duration & 2.27575 & 1 & 2.27575 & 1221.361 & $<0.0001$ & & 79.56 \\
\hline$B \times F$ & 0.012594 & 1 & 0.012594 & 6.758 & 0.0132 & & 0.440 \\
\hline$D \times E$ & 0.002006 & 1 & 0.002006 & 1.076 & 0.3060 & & 0.070 \\
\hline$D \times F$ & 0.001659 & 1 & 0.001659 & 0.890 & 0.3514 & & 0.058 \\
\hline$A^{2}$ & 0.022587 & 1 & 0.022587 & 12.122 & 0.0013 & & 0.789 \\
\hline$B^{2}$ & 0.00041 & 1 & 0.00041 & 0.220 & 0.6416 & & 0.014 \\
\hline$C^{2}$ & 0.001371 & 1 & 0.001371 & 0.736 & 0.3963 & & 0.047 \\
\hline$D^{2}$ & 0.004918 & 1 & 0.004918 & 2.639 & 0.1125 & & 0.171 \\
\hline$F^{2}$ & 0.022808 & 1 & 0.022808 & 12.240 & 0.0012 & & 0.797 \\
\hline Residual & 0.070805 & 38 & 0.070805 & & & & \\
\hline Lack of fit & 0.060554 & 33 & 0.001835 & 0.8950 & 0.6297 & $\begin{array}{l}\text { Not } \\
\text { significant }\end{array}$ & \\
\hline Pure error & 0.010251 & 5 & 0.00205 & & & & \\
\hline Cor total & 2.860169 & 53 & & & & & \\
\hline
\end{tabular}

current, which in turn causes larger size particle to be detached from the work material and therefore produces poor surface quality. The figure also shows that gradually the surface quality improves with increase in soaking duration. At the lower level of soaking duration, i.e., the untreated tool finds it difficult to dissipate the heat absorbed during machining owing to the poor thermal and electrical conductivity. As a result the machined surface of the tool tip gets damaged due to severe evaporation and melting from the tool tip. Damaged machined tip of tool causes non-uniform sparking between the electrodes, which in turn deteriorates the surface quality. On the other hand, when soaking duration increases, thermal conductivity and micro-hardness of the tool material also increase. Therefore the heat rejection capacity of the tools also increases, which in turn effects better surface integrity of tool, improved tool shape and uniform sparking on the machining spot, leading to improved surface quality on the machined surface.

Similarly, from the surface plot of surface roughness with soaking duration and pulse-on time, it can be noticed that surface roughness increases with increase in pulse-on time at a lower value of soaking duration. The increase in pulse duration enhances the spark energy between the electrode, which in turn facilitates detachment of large sized particle from the work material and the machined surface quality deteriorates. Likewise, from the surface plot

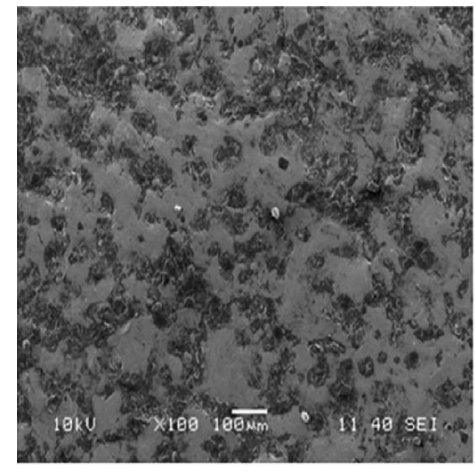

(a) Untreated electrode

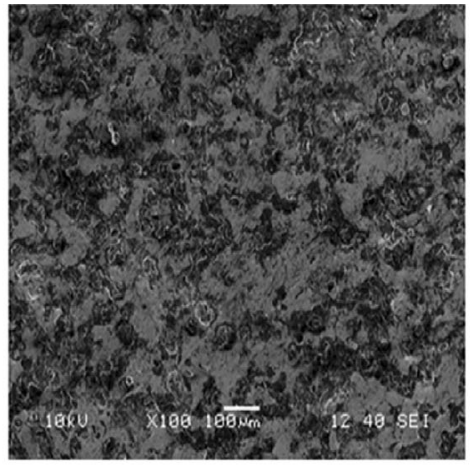

(b) Cryogenic-treated electrode with soaking duration of 24-hrs

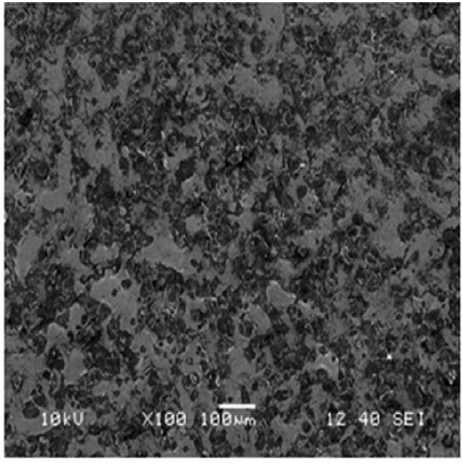

(c) Cryogenic-treated electrode with soaking duration of 36-hrs.

Figure 6. (a)-(c) Scanning electron microscope analysis of the electrode tip. 


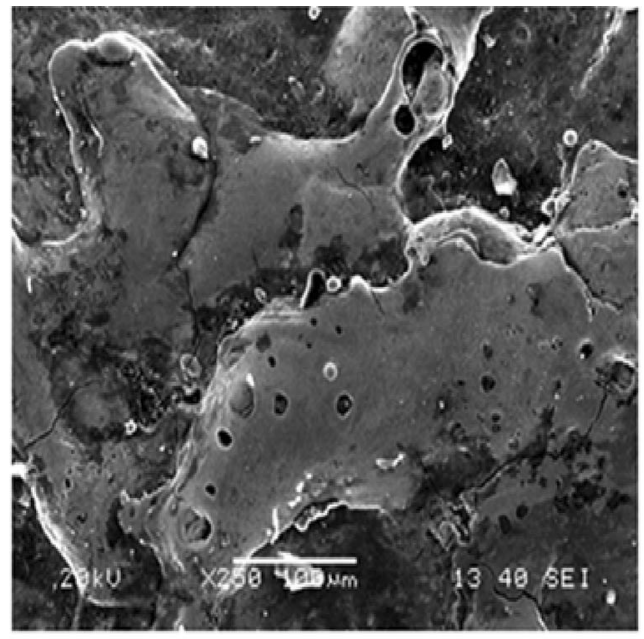

(a) SEM micrograph at $80 \mathrm{~V} / 5 \mathrm{~A} / 300 \mu \mathrm{s} / 80 \% / 0.2 \mathrm{bar} /$ Ohrs.

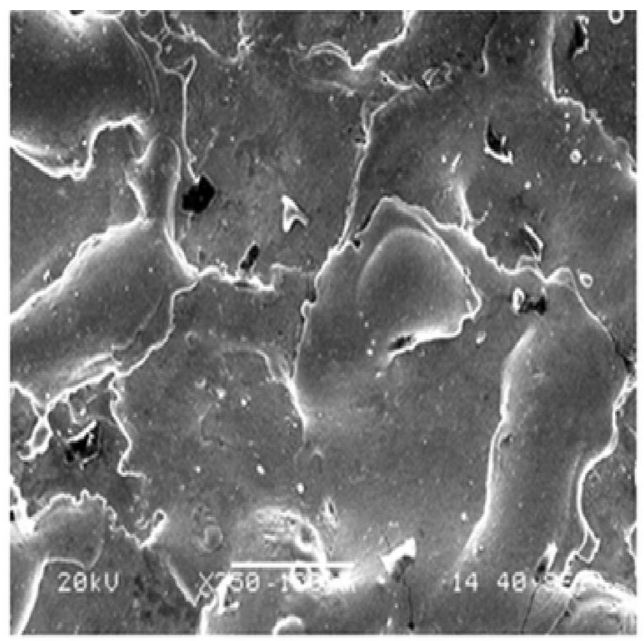

(b) SEM micrograph at $80 \mathrm{~V} / 5 \mathrm{~A} / 300 \mu \mathrm{s} / 80 \% / 0.2 \mathrm{bar} / 36 \mathrm{hrs}$.

Figure 7. $(a, b)$ SEM micrographs of the machined surface of the workpiece.

of duty factor and soaking duration it is observed that surface roughness increases very slowly with increase in duty factor due to increase in number of sparks per unit time. Open-circuit voltage and flushing pressure have minute effect on deviation of surface roughness.

Radial over-cut is a major performance measure as it directly leads to precise and accurate machining of the process. The surface plot of radial over-cut with soaking duration and discharge current is shown in figure 10. It shows that radial over-cut increases rapidly with the increase in value of discharge current for the untreated tool.
This is because increased discharge current significantly enhances the in-spark energy across the work surface and higher volume of material is eroded from the work material, resulting in wider crater to be formed on the machined surface, which in turn increases radial over-cut. The figure also indicates that radial over-cut varies inversely with soaking duration. The untreated tool finds it difficult to reject the heat absorbed during machining owing to poor thermal conductivity. As a result the roundness of the tool material is greatly damaged due to evaporation and melting. As the tool material looses its proper shape because of non-

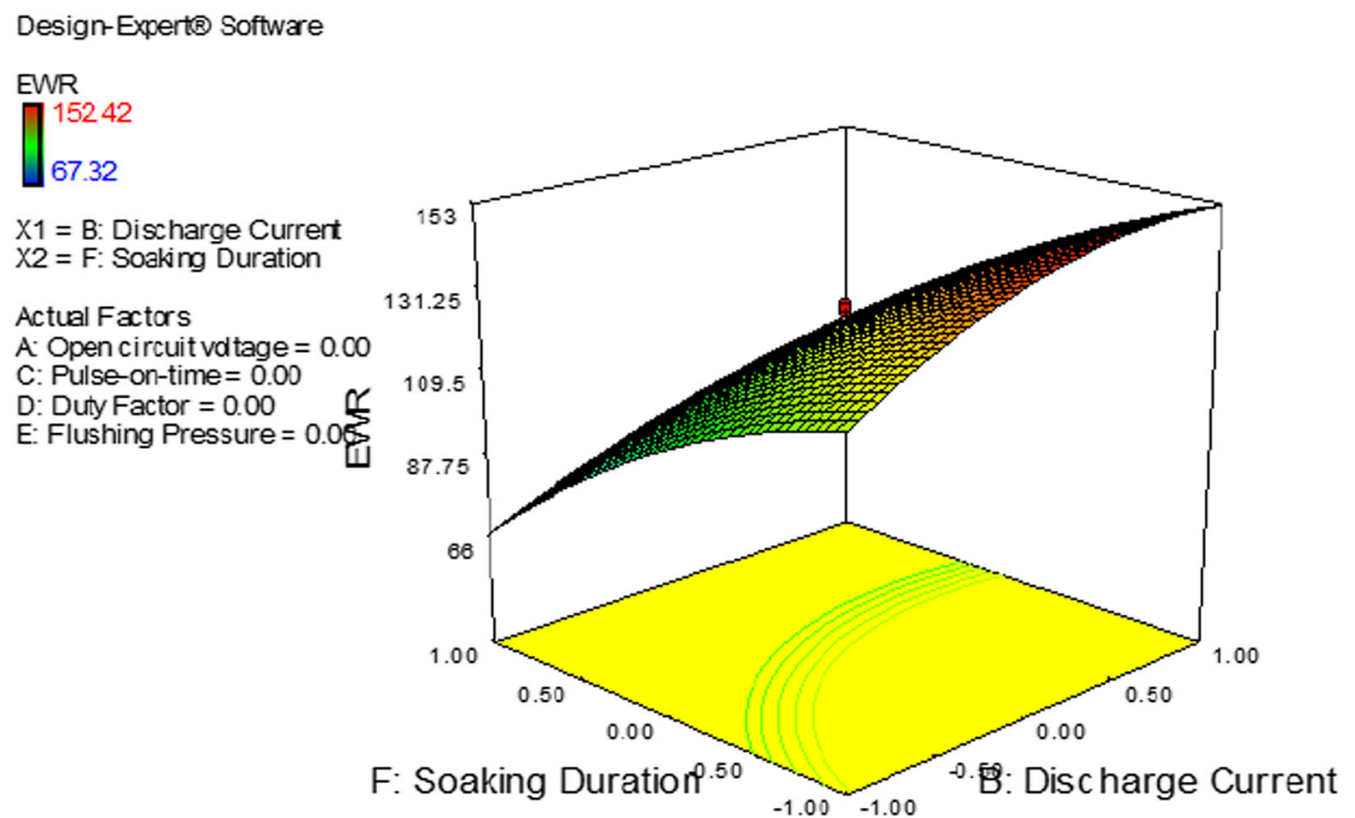

Figure 8. Surface plot of EWR with discharge current and soaking duration. 
Design-Expert@ Software

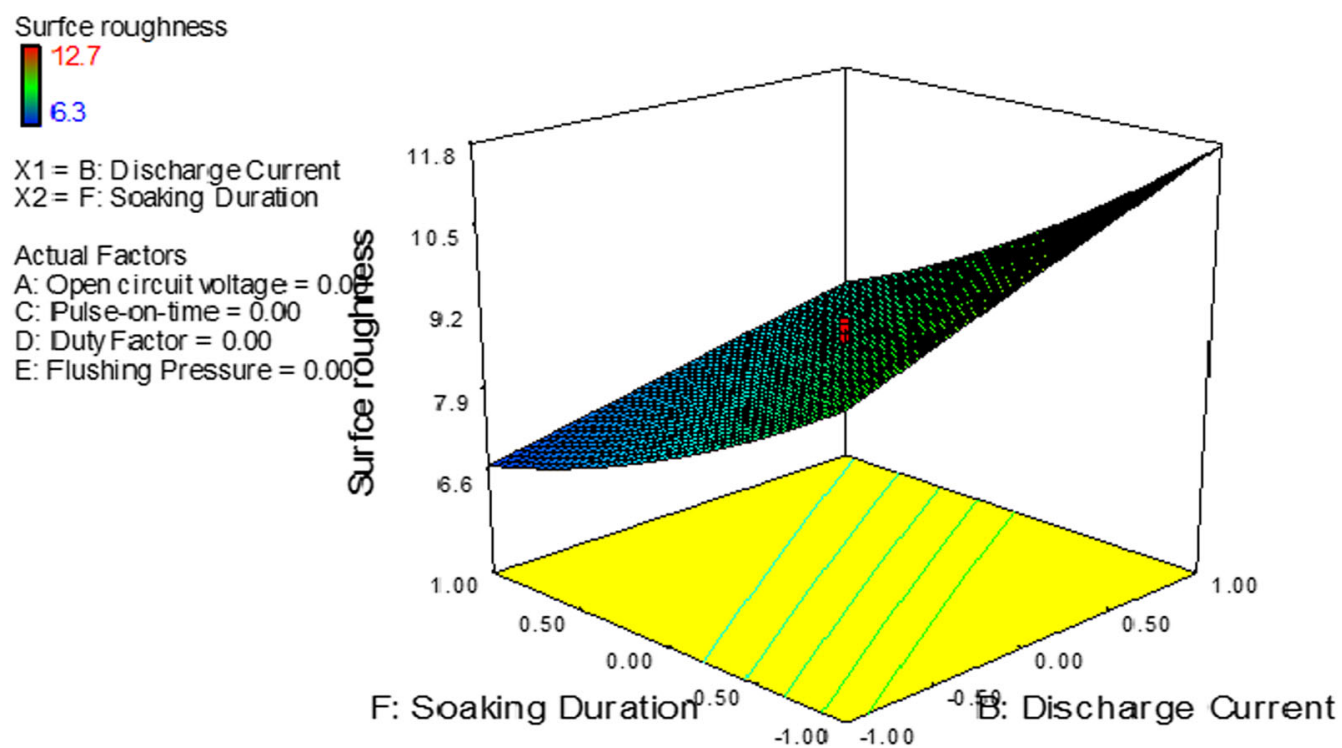

Figure 9. Surface plot of surface roughness with discharge current and soaking duration.

uniform sparking the production exactness of the drilled holes is inferior. On the other hand when the tools are treated up to 24-h soaking duration, the properties microhardness and thermal conductivity improve. As a result the heat rejection capacity improves, which helps in maintaining proper tool shape; because of uniform sparking the preciseness of the drilled hole increases. Further increase in soaking duration enhances the mechanical properties of the tool and the micro-structure becomes dense. Therefore the vaporization and melting from tool tip is reduced and the tool remains in proper shape. This results in uniform sparking on the machining spot and precise holes are produced at longer soaking duration.

Likewise, the surface plot of radial over-cut with pulseon time and duty factor indicates that radial over-cut shows an increasing trend with increase in both the variables. This is reasonable as increase in duty factor and pule-on time increases the spark energy significantly due to occurrence of a series of spark discharges. This in turn influences increase in MRR and effects increasing radial over-cut.

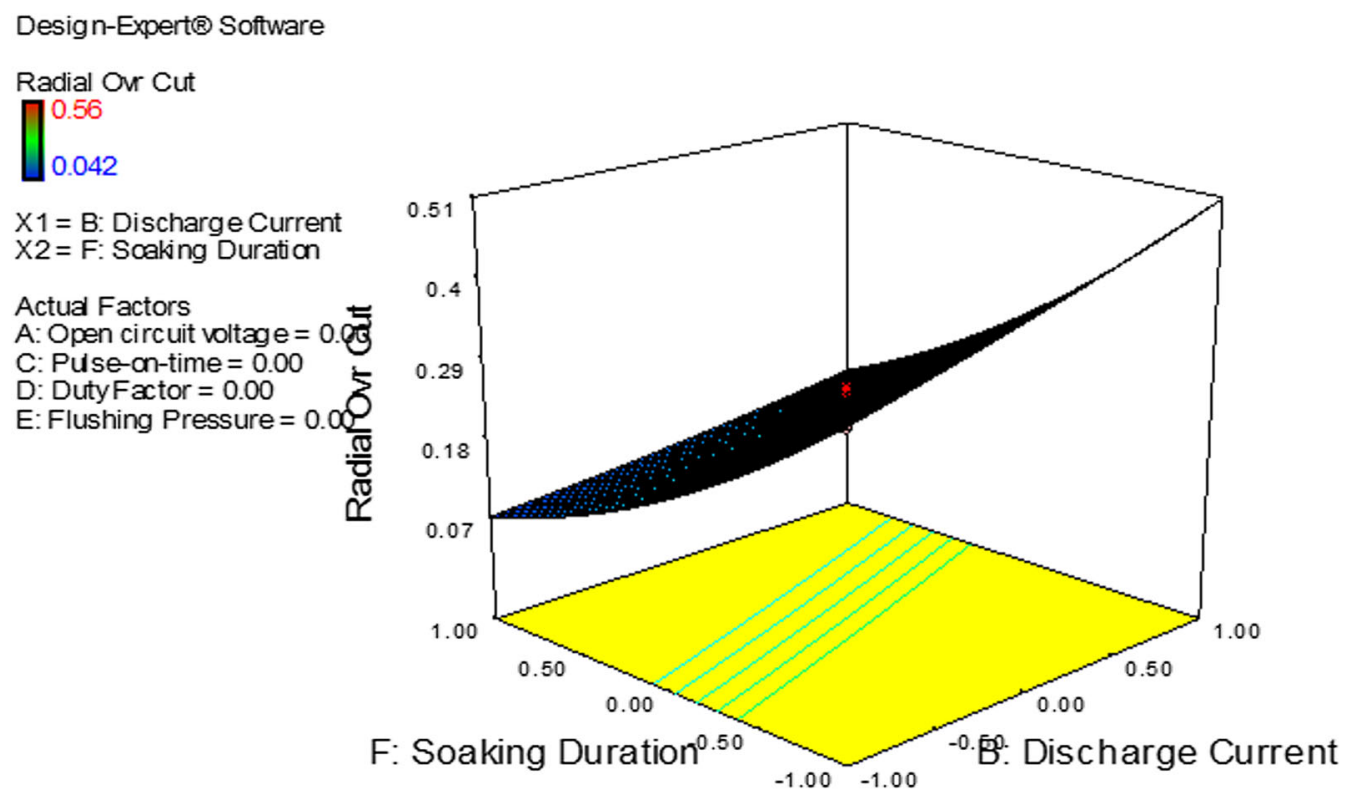

Figure 10. Surface plot of radial over-cut with discharge current and soaking duration. 

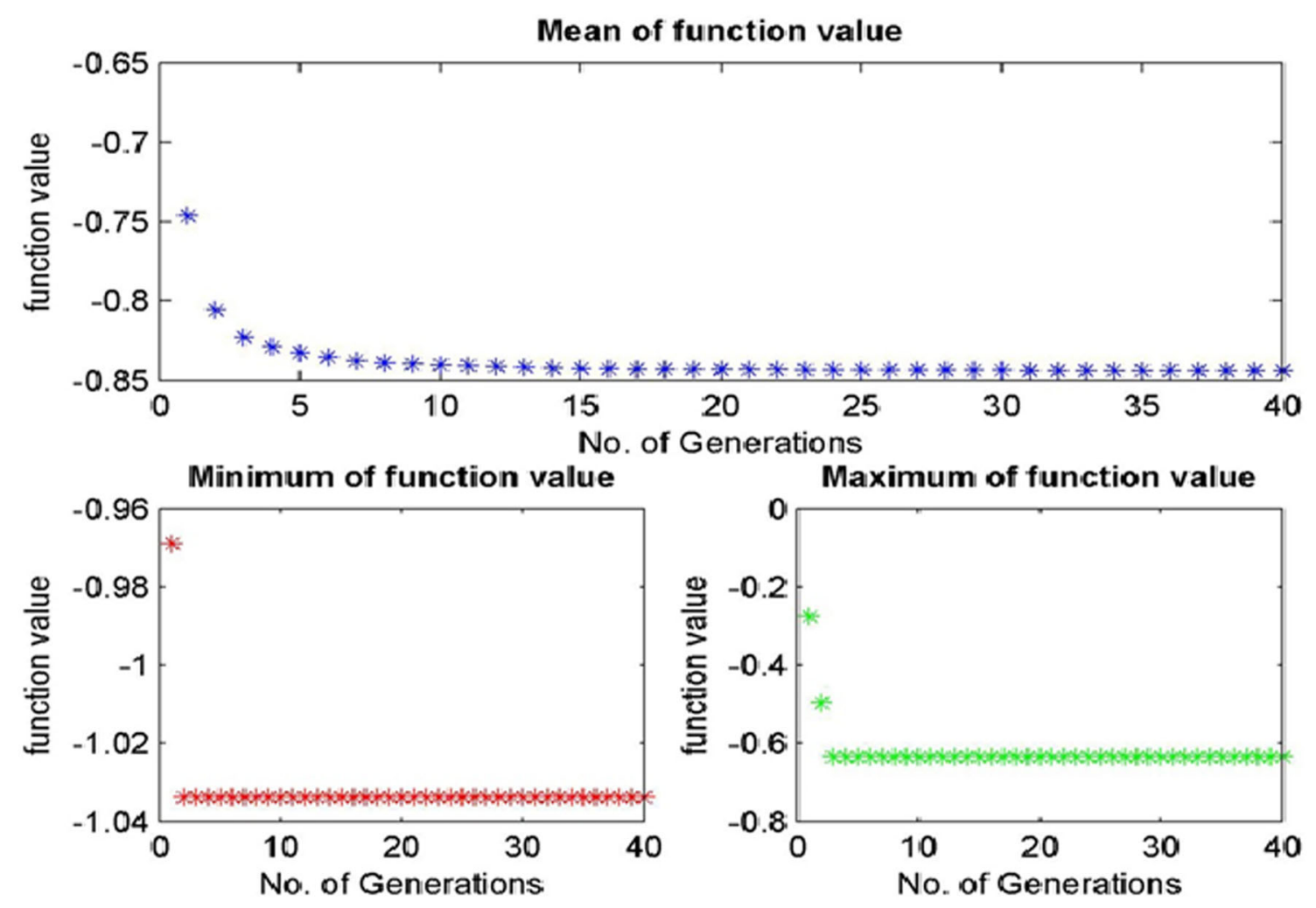

Figure 11. Convergence curve of TLBO algorithm.

In this work, the multiple performance measures are converted into an equivalent single performance measure by calculating the relative closeness coefficient $\left(C_{+}^{i}\right)$ by TOPSIS approach. The relative closeness coefficient is calculated with a preference order ranked between 0.01937 and 0.997541 with the highest preference on the order of 0.997541. A non-linear regression analysis is conducted relating relative closeness coefficient with process variables through using design expert 7 software, which has been shown in Eq. (19). The equation is written in terms of actual variables. For the statistical regression analysis the adjusted $\left(R^{2}\right)$ and coefficient of determination $\left(R^{2}\right)$ values are estimated to be $96.55 \%$ and $97.52 \%$, respectively, which confirms the validation of the model.

$$
\begin{aligned}
& \text { Relative closeness coefficient }\left(C_{+}^{i}\right) \\
& \quad=\{-1.25626-0.074333 A-0.11145 B \\
& \quad-1.611245 \times 10^{-4} C+0.12631 D-1.52609 E+0.15233 F \\
& +0.019838 B F+0.031669 D E+2.87973 \times 10^{-3} D F \\
& \quad+4.68611 \times 10^{-4} A^{2}+1.57863 \times 10^{-3} B^{2}-1.15469 \times 10^{-6} C^{2} \\
& \left.\quad-8.74663 \times 10^{-4} D^{2}-1.87728 E^{2}-0.047090 F^{2}\right\}
\end{aligned}
$$

In this work, the number of learners is treated as the population size and subjects taught are treated as the design variables. The learners results are the fitness values of the objective function, and the best result of these values is regarded as the best solution. In the present analysis, the initial population size is taken as twenty due to the presence of complexity in the problem. Several iterations were formed with various population size iterations to acquire the best result. Finally, the population size is selected as 40 , with 60 iterations. The convergence plot for relative closeness coefficients is shown in figure 11. From the plot, it can be clearly visualized that value of relative closeness coefficient is increased to 1.032 , which is better than the highest preference order obtained through TOPSIS approach in table 5. The optimal level of machining variables along with the relative closeness coefficient obtained through TLBO algorithm has been presented in table 7 .

\section{Confirmative test}

The optimal level of machining variables obtained through TLBO algorithm is verified by conducting confirmative tests for validation of the work. The confirmation test is carried out at the parametric setting $V=70 \mathrm{~V}, I_{p}=3 \mathrm{~A}, T_{\text {on }}=$ $100 \mu \mathrm{s}, \tau=80 \%, F_{p}=0.3$ and soaking duration= $36 \mathrm{~h}$ ) for the performance measures EWR, surface roughness and radial over-cut. The experimental relative closeness coefficient from the obtained performance measures is calculated and compared to the TLBO relative closeness 
Table 7. Confirmative test for the performance measures.

\begin{tabular}{|c|c|c|c|c|c|}
\hline $\begin{array}{l}\text { Process } \\
\text { variables }\end{array}$ & Unit & Value & $\begin{array}{c}\text { TLBO } \\
C_{+}^{i}\end{array}$ & $\begin{array}{c}\text { Experimental } \\
C_{+}^{i}\end{array}$ & $\begin{array}{l}\text { Error } \\
(\%)\end{array}$ \\
\hline $\begin{array}{l}A \text { - open-circuit } \\
\text { voltage }\end{array}$ & V & 70 & & & \\
\hline $\begin{array}{l}B \text {-discharge } \\
\text { current }\end{array}$ & A & 3 & & & \\
\hline $\begin{array}{l}C \text {-pulse-on } \\
\text { time }\end{array}$ & $\mu \mathrm{s}$ & 100 & & & \\
\hline$D$-duty factor & $\%$ & 80 & & & \\
\hline $\begin{array}{c}E \text {-flushing } \\
\text { pressure }\end{array}$ & bar & 0.3 & & & \\
\hline $\begin{array}{c}F \text {-cryogenic } \\
\text { treatment } \\
\text { soaking } \\
\text { duration }\end{array}$ & $\mathrm{h}$ & 36 & & & \\
\hline $\begin{array}{l}\text { Relative } \\
\text { closeness } \\
\text { coefficient }\end{array}$ & & & 1.032 & 1.007 & 2.171 \\
\hline
\end{tabular}

coefficient. It is observed that the difference between the two results is 2.171 percentages, which confirms the validation of the model. The confirmative test result along with optimal level of cutting variables and calculated error percentages of closeness coefficients has been provided in table 7 .

\section{Conclusions}

The present study explores the effect of deep cryogenic treatment soaking duration and shows that brass can be employed as an ideal EDM tool material after deep cryogenic treatment with longer soaking duration to machine hard materials like Inconel 718. Results clearly show significant enhancement of all the performance measures for the treated tools with longer soaking durations. In the second phase, a hybrid approach of TOPSIS in combination with TLBO algorithm has been proposed for achieving the best machining condition for EDM process. The optimal parametric level of machining variables obtained through the approach is validated by conducting confirmative tests predicting an error of 2.171 percentages between the experimental and computational results. From the experimental investigation, the following conclusions can be drawn.

1. Owing to deep cryogenic treatment the thermal conductivity and micro-hardness of the brass electrode increase. As a result the heat rejection capacity of the treated tools increases, which in turn increases the wearing resistance of the tool. Therefore, with improved wearing resistance, brass can be applied as an ideal electrode material to generate precise and accurate EDMed parts mainly in finishing operations.
2. The study revealed that substantial reduction for the non-beneficial performance measures can be obtained if the tools are subjected to soaking for extended duration, i.e., up to $36 \mathrm{~h}$. Owing to longer duration of soaking the EWR, surface roughness and radial overcut are drastically reduced up to $48.29 \%, 31.72 \%$ and $88.33 \%$, respectively, when comparisons are made between the experiment numbers 35 (machined with untreated tool) and 39 (machined with cryo-treated tool with soaking duration of $36 \mathrm{~h}$ ). Therefore it can be concluded that soaking duration is the utmost decisive variable to enhance performance measures of the EDM process.

3. SEM micrograph images clearly demonstrate that tools treated with extended soaking duration can maintain excellent surface integrity of the machined surface and can retain better initial shape in comparison with untreated tool.

4. Process variables, viz. pulse-on time, discharge current, soaking duration and duty factor, exhibit substantial effect on the machining characteristics.

5. Flushing pressure contributes little to the variation of the performance measures.

It is to be noted that the conclusions drawn from the study are valid for this particular work-tool combination only, i.e., for Inconel 718 as workpiece and brass as the electrode material. However, a generalized conclusion is drawn from the study, that if tool materials are treated for longer soaking duration their wearing resistance and shape retention are better owing to improvement of mechanical properties and this is applicable to all the materials irrespective of any machines or job shop or any other conditions. Moreover, depending upon the material properties and composition of different materials, the results and analysis may be different.

\section{Acknowledgements}

The experimental data collected for this study are based on the Doctoral thesis submitted to National Institute of Technology, Rourkela, authored by Dr. Chinmaya Prasad Mohanty, i.e., by the first author of this manuscript. The authors thank National Institute of Technology, Rourkela, India, for providing their facilities and resources to carry out the research work. It is hereby declared that the material present in the manuscript is the original research carried out by the authors. No part of this manuscript or the entire manuscript has been submitted to any conference or journal. The thesis has been also cited in the manuscript. For further clarification, the following link of the thesis submitted to National Institute of Technology, Rourkela, is also provided: http://ethesis.nitrkl.ac.in/6915/1/Chinmaya_ 511ME123_PhD_2015.pdf 


\section{References}

[1] Lee S and Li X 2001 Study of the effect of machining parameters on the machining characteristics in electrical discharge machining of tungsten carbide. J. Mater. Process. Technol. 115(3): 344-358

[2] Kuppan P, Narayanan S and Rajadurai A 2011 Effect of process parameters on material removal rate and surface roughness in electric discharge drilling of inconel 718 using graphite electrode. Int. J. Manuf. Technol. Manag. 23(3-4): 214-233

[3] Kumar S, Singh R, Singh T and Sethi B 2009 Surface modification by electrical discharge machining: a review. $J$. Mater. Process. Technol. 209(8): 3675-3687

[4] Kumar N, Kumar L, Tewatia H and Yadav R 2012 Comparative study for mrr on die-sinking edm using electrode of copper \& graphite. Int. J. Adv. Technol. Eng. Res. 2(2): $170-174$

[5] Åhman L 1984 Microstructure and its effect on toughness and wear resistance of laser surface melted and post heat treated high speed steel. Metall. Trans. A 15(10): 1829-1835

[6] Apachitei I, Tichelaar F, Duszczyk J and Katgerman L 2002 The effect of heat treatment on the structure and abrasive wear resistance of autocatalytic nip and nip-sic coatings. Surf. Coat. Technol. 149(2): 263-278

[7] Kim H, Miyaji F, Kokubo T and Nakamura T 1997 Effect of heat treatment on apatite-forming ability of ti metal induced by alkali treatment. J. Mater. Sci. Mater. Med. 8(6): 341-347

[8] Arockia Jaswin M and Mohan Lal D 2010 Optimization of the cryogenic treatment process for en 52 valve steel using the Grey-Taguchi method. Mater. Manuf. Process. 25(8): 842-850

[9] Kumar A, Maheshwari S, Sharma C and Beri N 2012 Machining efficiency evaluation of cryogenically treated copper electrode in additive mixed edm. Mater. Manuf. Process. 27(10): 1051-1058

[10] Jafferson J M and Hariharan P 2013 Machining performance of cryogenically treated electrodes in microelectric discharge machining: a comparative experimental study. Mater. Manuf. Process. 28(4): 397-402

[11] Kapoor J, Singh S and Khamba J S 2012 Effect of cryogenic treated brass wire electrode on material removal rate in wire electrical discharge machining. Proc. Inst. Mech. Eng. C J. Mech. Eng. Sci. 226(11):2750-2758

[12] Gill S S, Singh H, Singh R and Singh J 2010 Cryoprocessing of cutting tool materialsa review. Int. J. Adv. Manuf. Technol. 48(1): 175-192

[13] Gill S S and Singh J 2010 Effect of deep cryogenic treatment on machinability of titanium alloy (ti-6246) in electric discharge drilling. Mater. Manuf. Process. 25(6): 378-385

[14] Xu J, Liu Y, Wang J, Kui X, Gao Y and Xu Z 2007 A study on double glow plasma surface metallurgy mo-cr high speed steel of carbon steel. Surf. Coat. Technol. 201(9): 5093-5096

[15] Lal D M, Renganarayanan S and Kalanidhi A 2001 Cryogenic treatment to augment wear resistance of tool and die steels. Cryogenics 41(3): 149-155

[16] Collins D and Dormer J 1997 Deep cryogenic treatment of a d 2 cold-work tool steel. Heat Treat. Metals (UK) 24(3): 71-74

[17] Mohanty C P, Mahapatra S S and Singh M R 2016 A particle swarm approach for multi-objective optimization of electrical discharge machining process. J. Intell. Manuf. 27(6): 1171-1190

[18] Padhee S, Nayak N, Panda S, Dhal P and Mahapatra S 2012 Multi-objective parametric optimization of powder mixed electro-discharge machining using response surface methodology and non-dominated sorting genetic algorithm. Sadhana, pp. 1-18

[19] Prabhu S and Vinayagan B K 2013 Multi objective optimisation of swcnt-based electrical discharge machining process using grey relational and fuzzy logic analysis. Int. J. Mach. Mach. Mater. 13(4): 439-463

[20] Dewangan S and Biswas C K 2013 Optimisation of machining parameters using grey relation analysis for edm with impulse flushing. Int. J. Mechatron. Manuf. Syst. 6(2): 144-158

[21] El-Taweel T A and Hewidy M S 2009 Enhancing the performance of electrical-discharge machining via various planetary modes. Int. J. Mach. Mach. Mater. 5(2-3):308-320

[22] Dewangan S, Gangopadhyay S and Biswas C 2015 Study of surface integrity and dimensional accuracy in edm using fuzzy topsis and sensitivity analysis. Measurement 63: 364-376

[23] Puhan D, Mahapatra S S, Sahu J and Das L 2013 A hybrid approach for multi-response optimization of non-conventional machining on alsic p mmc. Measurement 46(9): 3581-3592

[24] Selvarajan L, Narayanan C S, Jeyapaul R and Manohar M 2016 Optimization of edm process parameters in machining si 3 n 4-tin conductive ceramic composites to improve form and orientation tolerances. Measurement 92: 114-129

[25] Srivastava V and Pandey P M 2011 Study of the cryogenically cooled electrode shape in electric discharge machining process. In: Conference Proceedings of the World Academy of Science, Engineering and Technology, vol. 60, pp. $1017-1021$

[26] Abdulkareem S, Khan A A and Konneh M 2009 Reducing electrode wear ratio using cryogenic cooling during electrical discharge machining. Int. J. Adv. Manuf. Technol. 45(11): $1146-1151$

[27] Srivastava V and Pandey P M 2012 Performance evaluation of electrical discharge machining (edm) process using cryogenically cooled electrode. Mater. Manuf. Process. 27(6): 683-688

[28] Joshi S and Pande S 2009 Development of an intelligent process model for edm. Int. J. Adv. Manuf. Technol. 45(3): $300-317$

[29] Joshi S N and Pande S 2010 Thermo-physical modeling of die-sinking edm process. J. Manuf. Process. 12(1): 45-56

[30] Paramashivan S S, Mathew J and Mahadevan S 2012 Mathematical modeling of aerosol emission from die sinking electrical discharge machining process. Appl. Math. Modell. 36(4): 1493-1503

[31] Chen Y and Mahdivian SM 2000 Analysis of electro-discharge machining process and its comparison with experiments. J. Mater. Process. Technol. 104(1): 150-157

[32] Mohanty C P, Sahu J and Mahapatra S S 2013 Thermalstructural analysis of electrical discharge machining process. Proc. Eng. 51: 508-513

[33] Singh S, Maheshwari S and Pandey P 2004 Some investigations into the electric discharge machining of hardened 
tool steel using different electrode materials. J. Mater. Process. Technol. 149(1): 272-277

[34] Kumar V and Kumar P 2015 Experimental investigation of the process parameters in cryogenic cooled electrode in edm. J. Mech. Sci. Technol. 29(9): 3865-3871

[35] Tzeng G H and Huang J J 2011 Multiple attribute decision making: methods and applications. Chapman and Hall/ CRC

[36] Jayakumar D N and Venkatesh P 2014 Glowworm swarm optimization algorithm with topsis for solving multiple objective environmental economic dispatch problem. Appl. Soft Comput. 23: 375-386

[37] Behzadian M, Otaghsara S K, Yazdani M and Ignatius J 2012 A state-of the-art survey of topsis applications. Expert Syst. Appl. 39(17): 13051-13069

[38] Mogale D, Dolgui A, Kandhway R, Kumar S K and Tiwari M K 2017 A multi-period inventory transportation model for tactical planning of food grain supply chain. Comput. Ind. Eng. 110: 379 - 394

[39] Maiyar L M and Thakkar J J 2017 A combined tactical and operational deterministic food grain transportation model: Particle swarm based optimization approach. Comput. Ind. Eng. 110: $30-42$

[40] Rao R V, Rai D P and Balic J 2017 A multi-objective algorithm for optimization of modern machining processes. Eng. Appl. Artif. Intell. 61: 103 - 125

[41] Mogale D, Kumar S K, Mrquez F P G and Tiwari M K 2017 Bulk wheat transportation and storage problem of public distribution system. Comput. Ind. Eng. 104: 80 - 97
[42] Rao R V and Savsani V J 2012 Mechanical design optimization using advanced optimization techniques. Springer Science \& Business Media

[43] Rao R V, Savsani V J and Vakharia D P 2012 Teachinglearning-based optimization: an optimization method for continuous non-linear large scale problems. Inf. Sci. 183(1): 1-15

[44] Li J-Q, Pan Q-K and Mao K 2015 A discrete teachinglearning-based optimisation algorithm for realistic flowshop rescheduling problems. Eng. Appl. Artif. Intell. 37:279-292

[45] Ghasemi M, Ghanbarian M M, Ghavidel S, Rahmani S and Moghaddam E M (2014) Modified teaching learning algorithm and double differential evolution algorithm for optimal reactive power dispatch problem: a comparative study. Inf. Sci. 278: 231-249

[46] Tiwari A and Pradhan M 2017 Applications of tlbo algorithm on various manufacturing processes: a review. Materials Today: Proceedings, vol. 4, no. 2, Part A, pp. 1644 - 1652, 2017, In: 5th International Conference of Materials Processing and Characterization (ICMPC 2016)

[47] Rao R V, More K C, Taler J and Ocłoń P 2016 Optimal design of stirling heat engine using an advanced optimization algorithm. Sadhana 41(11): 1321-1331

[48] Rao R V, Savsani V J and Vakharia D 2011 Teachinglearning-based optimization: a novel method for constrained mechanical design optimization problems. Comput. Aided Des. 43(3): 303-315

[49] Mohanty C P 2015 Studies on some aspects of multi-objective optimization: a case study of electrical discharge machining process, Ph.D. dissertation 